\title{
ECG and Echocardiographic Findings of Athletes in Bamako-A Study among 227 Footballers
}

\author{
Ibrahima Sangare ${ }^{*}$, Hamidou Oumar Bâ1, Youssouf Camara², Ichaka Menta1, Noumou Sidibé1, \\ Souleymane Coulibaly ${ }^{3}$, Aladji Traoré1, Fousseyni Coulibaly ${ }^{1}$, Ilo Diall ${ }^{3}$, \\ Lydie Bérenice S. Sangaré4, Hamidou Camara ${ }^{1}$, Adama Sogodogo', Mohamed A. C. Cissé5, \\ Mamadou Bocary Diarra6, Massama Konaté5, Kassoum M. Sanogo' ${ }^{1}$, Boubakar A. Diallo ${ }^{3}$
}

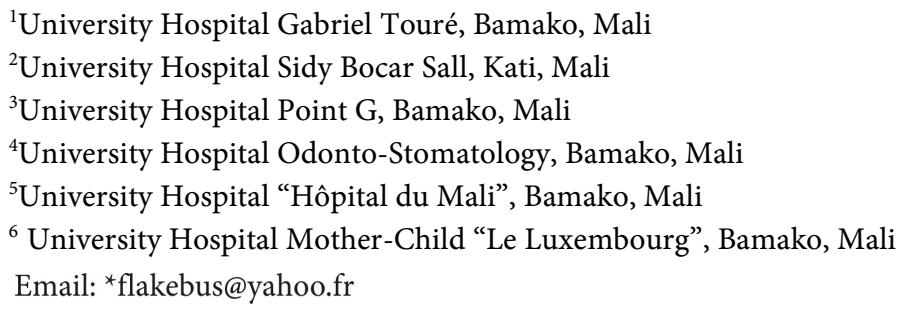

How to cite this paper: Sangare, I., Bâ, H.O., Camara, Y., Menta, I., Sidibé, N., Coulibaly, S., Traoré, A., Coulibaly, F., Diall, I., Sangaré, L.B.S., Camara, H., Sogodogo, A., Cissé, M.A.C., Diarra, M.B., Konaté, M., Sanogo, K.M. and Diallo, B.A. (2019) ECG and Echocardiographic Findings of Athletes in Bamako-A Study among 227 Footballers. World Journal of Cardiovascular Diseases, 9, 31-41. https://doi.org/10.4236/wjcd.2019.91004

Received: December 17, 2018

Accepted: January 19, 2019

Published: January 22, 2019

Copyright $\odot 2019$ by author(s) and Scientific Research Publishing Inc. This work is licensed under the Creative Commons Attribution International License (CC BY 4.0).

http://creativecommons.org/licenses/by/4.0/

\begin{abstract}
Background: A cardiovascular assessment is rarely performed among athletes despite more and more frequently reported fatal events. Most of these accidents are of cardiovascular origin. Moreover, data on ECG or Echocardiography are rare in our context justifying our study to assess electrical and echocardiographic pattern among high-level footballer in Bamako. Methods: It was a cross-sectional study conducted in Bamako from April 2015 to March 2016 among high-level footballers aged 14 to 35 years old without distinction of sex with at least 10 hours weekly training since one year. The ECG and echocardiographies were recorded respectively with a 12-lead CONTEC and an ATL 5000 echocardiographic machine. Each ECG record was analyzed by a cardiologist in accordance with the Seattle 2013 criteria and those pathological reviewed by a second cardiologist according to the same criteria and definitively classified as normal (physiological) or abnormal ECG (requiring complementary explorations). A third cardiologist was associated in case of discordance of the first results. The collected data were inserted in a Microsoft Excel sheet and analyzed with SPSS version 20. Chi Square and Fisher statistical tests were used to compare our results. The significance level was set at 0.05 . Results: We collected data of 227 top footballers with male sex represented in $90.3 \%$ giving a sex ratio of 3.04. Means for age, weight, height, body mass index (BMI) were respectively 22 years, $69.90 \mathrm{~kg}, 177.21$
\end{abstract}


$\mathrm{cm}$ and $22.21 \mathrm{~kg} / \mathrm{m}^{2}$. Sinus bradycardia was found in a proportion of $45.8 \%$ more represented in the age group of 30 and more years $(p=0.275)$. First-degree atrioventricular block (AVB) was present in $19.4 \%$. Short PR was found in $0.4 \%$ of the sample. Left ventricular hypertrophy (LVG) according to the Sokolow index was found in $70.5 \%$ (96.9\% males and 3.1\% females) with $\mathrm{p}<0.0001$. QTc was prolonged in $27.3 \%$ (28.8\% by men and $13.6 \%$ by women with $\mathrm{p}=0.1$ ) and mostly in the age group of 30 and more with $53.3 \%$ and p-value of 0.077. Conclusion: Many electrical and echocardiographic signs of cardiac adaptation were found in our sample and must lead to a closer follow-up of these trained footballers to avoid or prevent dramatic cardiovascular events.

\section{Keywords}

Sport, Football, Bamako, ECG, Echocardiography

\section{Introduction}

Regular sports practice has undeniable beneficial effects for health in general and singularly for the cardiovascular system. Regular, intense and prolonged physical activity, although beneficial, leads to functional, electrical and morphological cardiovascular changes. These in high-level athletes' observed cardiovascular changes are termed "athlete's hearts" and are benign [1]. However, the risk of a cardiovascular event is increased during an intense sport practice and may lead to unmask an underlying heart disease. The causes of sudden death on sports fields are cardiovascular in $85 \%-90 \%$ and usually secondary to cardiac arrhythmias [2] [3] [4] [5].

In 2005, European experts in sports cardiology, exercise physiology, rehabilitation of myocardial and pericardial diseases recommended the completion of an ECG between 12 and 35 years for any applicant for a sports license and this would be repeated every two years [6].

In France, the mandatory medical check-up of a top athlete includes a half-yearly examination by a sports doctor, an annual rest ECG and transthoracic echocardiography once in the career.

High level sport practice in Mali suffers from some organizational problems. A cardiovascular assessment is rarely performed in this environment despite more and more frequently reported fatal events. Most of these accidents are of cardiovascular origin [7] [8]. Moreover, data on ECG or Echocardiography are rare in our context justifying our study to assess electrical and echocardiographic pattern among high-level footballer in Bamako.

\section{Materials and Methods}

It was a cross-sectional study conducted in Bamako from April 2015 to March 2016 among high-level footballers.

A minimal sample size was calculated using following formula: 


$$
\text { Sample size }=\frac{Z_{1-\alpha / 2^{2}} p(1-p)}{d^{2}}=\frac{1.96^{2} \times 0.15(1-0.15)}{0.05^{2}}=195
$$

with $Z_{1-\alpha / 2^{2}}=1.96, p=15 \%, d=5 \%$.

\subsection{Selection Criteria}

After explaining the purpose and how the study will be conducted, participants were recruited in training centers in Bamako and included footballer based on following criteria:

- Age between 14 and 35 years without distinction of sex;

- At least 10 hours regularly weekly training since one year;

- Consent to participate in the study.

\subsection{Data Collection}

All participants underwent the same procedure:

- They were first asked for cardiac symptoms, family history of known cardiac disease followed by cardiovascular examination in the athlete's training sites;

- After that a rest ECG and two-dimensional transthoracic Echocardiography (TTE) were performed in medical facilities.

The ECG and echocardiographies were recorded respectively with a 12-lead CONTEC and an ATL 5000 echocardiographic machines.

Each ECG record was analyzed by a cardiologist in accordance with the Seattle 2013 criteria and those pathological reviewed by a second cardiologist according to the same criteria and definitively classified as normal (physiological) or abnormal ECG (requiring complementary explorations). A third cardiologist was associated in case of discordance of the first results.

For echocardiography, following values were considered as normal.

- Interventricular septum (IVS) : thickness less than $11 \mathrm{~mm}$;

- Posterior wall (PW): thickness between $9 \mathrm{~mm}$ and $10 \mathrm{~mm}$;

- Indexed LV: less than $28 \mathrm{~mm}$ in women and less than $30 \mathrm{~mm}$ in men;

- LVEF: greater than or equal to $55 \mathrm{~mm}$ in men as well as in women.

A survey formulary was used to collect data on socio-demographic, physical examination including data on cardiovascular auscultation, blood pressure, ECG and echocardiography records.

\subsection{Data Processing}

The collected data were inserted in a Microsoft Excel sheet and analyzed with SPSS version 20. Chi Square and Fisher statistical tests were used to compare our results. The significance level was set at 0.05 .

\section{Results}

We collected data of 227 top footballers, male sex representing $90.3 \%$ what give a sex ratio of 3.04. Means for age, weight, height, body mass index (BMI) were respectively 22.18 years, $69.90 \mathrm{~kg}, 177.21 \mathrm{~cm}$ and $22.21 \mathrm{~kg} / \mathrm{m}^{2}$ (Table 1 ). 
Twenty-one participants (all male) were obese based on BMI of whom 57.1\% in the age group 20 and 29 years with $p=0.003$ ).

Sinus bradycardia was found in a proportion of $45.8 \%$ (47.8\% were men and $27.3 \%$ women with $\mathrm{p}=0.168)$ (Diagram 1$)$. It was more represented in the age group of 30 and more years (Diagram 2), but not significantly ( $\mathrm{p}=0.275$ ).

First-degree atrioventricular block (AVB1) was present in $19.4 \%$ (20.5\% by men and $09.1 \%$ by women with $\mathrm{p}=0.409$ ) and short PR in $0.4 \%$. AVB1 was noted in 33.30 of footballers under 20 years whereas short PR was found among footballers about 30 years (Table 2).

A complete right bundlebranch block (RBBB) was present in $14.7 \%$ of cases. Left ventricular hypertrophy (LVG) according to the Sokolow index accounted for $70.5 \%$ (96.9\% males and $3.1 \%$ females) with $\mathrm{p}<0.0001$.

QTc was prolonged in $27.3 \%$ (28.8\% by men and $13.6 \%$ by women with $\mathrm{p}=$ 0.1 ) and mostly in the age group of 30 and more with $53.3 \%$ and p-value of 0.077 (Table 3).

Heart rate (HR) was significantly higher in the female group (66.27 against 60.05 in the male group $p=0.005$ ). There was no significantly difference between age groups. Means for PR duration, corrected QT and QRS duration showed no difference between sex and age group (Table 4).

ST segment elevation was observed in $70.9 \%$ of cases $(97.5 \%$ of men and $2.5 \%$ of women) with $\mathrm{p}<0.0001$.

The inter ventricular septum (IVS) was thickened in $10.7 \%$ of cases, all male participants and more frequent between 20 and 30 years (17\%). The posterior wall was normal in $99.5 \%$ of cases. The left ventricular ejection fraction (EF) was less than $55 \%$ in $19.3 \%$ of cases ( 21 males versus 2 females) with $\mathrm{p}=0.865$. Most echocardiographic data were significantly different between both sexes and between age groups (Table 5). Values for aorta, Left atrium (LA), left ventricle (LV) size and mass, isovolumetric relaxation time were higher for men and also increased with age.

Table 1. Means of demographics according to sex and age group for 227 athletes.

\begin{tabular}{|c|c|c|c|c|c|c|}
\hline \multicolumn{2}{|c|}{ Variables } & \multirow{2}{*}{$\begin{array}{c}\text { Age } \\
21.05\end{array}$} & \multirow{2}{*}{$\begin{array}{c}\text { Weight } \\
56.95\end{array}$} & \multirow{2}{*}{$\begin{array}{c}\text { Height } \\
166.09\end{array}$} & \multirow{2}{*}{$\begin{array}{c}\text { BMI* }^{*} \\
20.65\end{array}$} & \multirow{2}{*}{$\begin{array}{c}\text { Mean } \text { AP }^{\star *} \\
84.39\end{array}$} \\
\hline & $\mathrm{F}(22)$ & & & & & \\
\hline Sex & M (205) & 22.30 & 71.29 & 178.4 & 22.37 & 89.69 \\
\hline \multirow{5}{*}{$\begin{array}{c}\text { Age group } \\
\text { (years) }\end{array}$} & $\mathrm{P}$ & 0.201 & $<0.0001$ & $<0.0001$ & $<0.0001$ & $<0.006$ \\
\hline & $<20(68)$ & 17.56 & 66.68 & 176.04 & 21.48 & 88.65 \\
\hline & $20-29(144)$ & 23.30 & 70.86 & 177.76 & 22.37 & 89.12 \\
\hline & $\geq 30$ (15) & 32.40 & 75.27 & 177.20 & 23.94 & 92.13 \\
\hline & $\mathrm{P}$ & $<0.0001$ & $<0.0001$ & 0.307 & $<0.0001$ & 0.361 \\
\hline \multicolumn{2}{|c|}{ All sample } & 22,18 & 69.90 & 177.21 & 22.21 & 89.18 \\
\hline
\end{tabular}

${ }^{\star} \mathrm{BMI}$ : body mass index; ${ }^{\star *} \mathrm{AP}$ : arterial pressure. 
Table 2. Evaluation of PR duration according to sex and age group in the sample of 227 athletes.

\begin{tabular}{|c|c|c|c|c|c|}
\hline \multirow{2}{*}{\multicolumn{2}{|c|}{ Variables }} & \multicolumn{3}{|c|}{ PR duration } & \multirow{2}{*}{$\mathrm{p}$} \\
\hline & & Long & Normal & Short & \\
\hline \multirow[t]{3}{*}{ Sex } & $\mathrm{F}$ & 9.10 & 90.90 & 0.00 & \multirow{3}{*}{0.409} \\
\hline & & & & & \\
\hline & $\mathrm{M}$ & 20.50 & 79.00 & 0.50 & \\
\hline \multirow[t]{3}{*}{$\begin{array}{c}\text { Age group } \\
\text { (years) }\end{array}$} & $<20$ & 33.30 & 66.70 & 0.00 & \multirow{3}{*}{0.575} \\
\hline & $20-29$ & 16.20 & 83.80 & 0.00 & \\
\hline & $\geq 30$ & 19.40 & 79.90 & 0.70 & \\
\hline \multicolumn{2}{|c|}{ Entire sample } & 19.4 & 80.20 & 04.00 & - \\
\hline
\end{tabular}

Table 3. Evaluation of corrected QT duration based on Bazett formulaaccording to sex and age group in the sample of 227 athletes.

\begin{tabular}{|c|c|c|c|c|c|}
\hline \multirow{2}{*}{\multicolumn{2}{|c|}{ Variables }} & \multicolumn{3}{|c|}{ QT duration } & \multirow{2}{*}{$\mathrm{p}$} \\
\hline & & \multirow{2}{*}{\begin{tabular}{r|} 
Long \\
13.6
\end{tabular}} & \multirow{2}{*}{$\begin{array}{c}\text { Normal } \\
86.4\end{array}$} & \multirow{2}{*}{$\begin{array}{c}\text { Short } \\
0\end{array}$} & \\
\hline Sex & $\mathrm{F}$ & & & & \\
\hline & $\mathrm{M}$ & 28.8 & 64.4 & 6.8 & 0.1 \\
\hline \multirow{3}{*}{$\begin{array}{c}\text { Age group } \\
\text { (years) }\end{array}$} & $<20$ & 22.1 & 75 & 2.9 & \multirow{3}{*}{0.077} \\
\hline & $20-29$ & 27.1 & 65.3 & 7.6 & \\
\hline & $\geq 30$ & 53.3 & 40 & 6.7 & \\
\hline \multicolumn{2}{|c|}{ Entire sample } & 27.3 & 66.5 & 6.2 & \\
\hline
\end{tabular}

Table 4. Means distribution of ECG data according to sex and age group for 227 athletes.

\begin{tabular}{|c|c|c|c|c|c|}
\hline \multicolumn{2}{|c|}{ Variables } & \multirow{2}{*}{$\frac{\mathrm{HR}^{*}(/ \mathrm{min})}{66.27}$} & \multirow{2}{*}{$\frac{\operatorname{PR}\left(\mathrm{ms}^{\star *}\right)}{179.55}$} & \multirow{2}{*}{$\frac{\mathrm{QTc}^{* * *}(\mathrm{~ms})}{426.58}$} & \multirow{2}{*}{$\begin{array}{c}\text { QRS (ms) } \\
81.36\end{array}$} \\
\hline Sex & $\mathrm{F}(22)$ & & & & \\
\hline & M (205) & 60.05 & 199.05 & 426.17 & 82.59 \\
\hline & $\mathrm{P}$ & 0.005 & 0.153 & 0.969 & 0.631 \\
\hline \multirow[t]{4}{*}{$\begin{array}{c}\text { Age group } \\
\text { (years) }\end{array}$} & $<20(68)$ & 62.96 & 186.18 & 428.10 & 82.06 \\
\hline & $20-29(144)$ & 59.87 & 200.88 & 423.64 & 82.14 \\
\hline & $\geq 30$ (15) & 57.80 & 211.33 & 438.18 & 87.33 \\
\hline & $\mathrm{P}$ & 0.056 & 0.168 & 0.446 & 0.225 \\
\hline All sample & & 60.66 & 197.16 & 426.21 & 82.47 \\
\hline
\end{tabular}

${ }^{*}$ HR: heart rate; ${ }^{* *}$ : milliseconds; ${ }^{* *}$ QTc: corrected QT based on Bazett formula. 
Table 5. Means of Echocardiography data according to sex and age group for 227 athletes.

\begin{tabular}{|c|c|c|c|c|c|c|c|c|c|c|}
\hline \multicolumn{2}{|c|}{ Variables } & \multirow{2}{*}{$\begin{array}{l}\begin{array}{l}\text { Aorta } \\
(\mathrm{mm})\end{array} \\
27.05\end{array}$} & \multirow{2}{*}{$\begin{array}{l}\mathrm{LA}^{*} \\
(\mathrm{~mm})\end{array}$} & \multirow{2}{*}{$\begin{array}{l}\mathrm{LV}^{* *} \\
(\mathrm{~mm}) \\
47.36\end{array}$} & \multirow{2}{*}{$\begin{array}{c}\mathrm{LVind}^{+} \\
\mathrm{mm} / \mathrm{m}^{2}\end{array}$} & \multirow{2}{*}{$\begin{array}{c}\mathrm{EF}_{\mathrm{t}}^{++} \\
(\%) \\
64.50\end{array}$} & \multirow{2}{*}{$\begin{array}{c}\begin{array}{c}\mathrm{LV} \\
(\mathrm{g})\end{array} \\
115.27\end{array}$} & \multirow{2}{*}{$\begin{array}{l}\text { E/A } \\
2.09\end{array}$} & \multirow{2}{*}{ 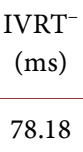 } & \multirow{2}{*}{$\begin{array}{c}\mathrm{RV}^{-} \mathrm{LV}^{-} \\
0.42\end{array}$} \\
\hline & $\mathrm{F}(22)$ & & & & & & & & & \\
\hline \multirow[t]{3}{*}{ Sex } & M (205) & 31.14 & 34.72 & 51.30 & 27.26 & 61.77 & 191.37 & 1.76 & 78.65 & 0.39 \\
\hline & $\mathrm{P}$ & $<0.001$ & 0.002 & 0.001 & 0.007 & 0.017 & $<0.001$ & 0.007 & 0.874 & 0.252 \\
\hline & $<20(68)$ & 30.22 & 33.78 & 50.43 & 27.83 & 62.34 & 170.25 & 1.89 & 75.43 & 0.37 \\
\hline \multirow{3}{*}{$\begin{array}{c}\text { Age } \\
\text { group } \\
\text { (years) }\end{array}$} & $20-29(144)$ & 30.62 & 34.67 & 51.25 & 27.41 & 61.80 & 187.80 & 1.77 & 80.31 & 0.41 \\
\hline & $\geq 30$ (15) & 34.33 & 35.33 & 50.00 & 26.12 & 62.93 & 209.80 & 1.59 & 76.67 & 0.41 \\
\hline & $\mathrm{P}$ & $<0.001$ & 0.232 & 0.479 & 0.171 & 0.606 & 0.004 & 0.103 & 0.036 & 0.007 \\
\hline \multicolumn{2}{|c|}{ Entiresample } & 30.74 & 34.44 & 50.92 & 27.45 & 62.04 & 184.00 & 1.79 & 78.61 & 0.40 \\
\hline
\end{tabular}

${ }^{\star} \mathrm{LA}$ : left atrium; ${ }^{\star *} \mathrm{LV}$ : left ventricle; +: indexed left ventricle; ++: EF Teichholz; -: isovolumetric relaxation time; --: RV/LV: ratio right ventricle/left ventricle.

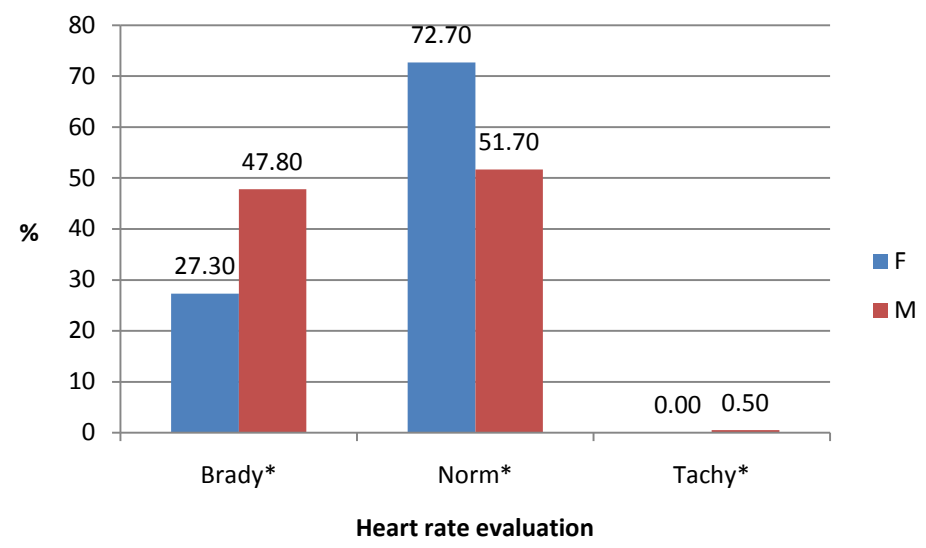

Diagram 1. Heart rate evaluation according to sex for 227 athletes. *Brady: bradycardia; Norm: normal heart rate; Tachy: tachycardia; $p$ $=0.168$.

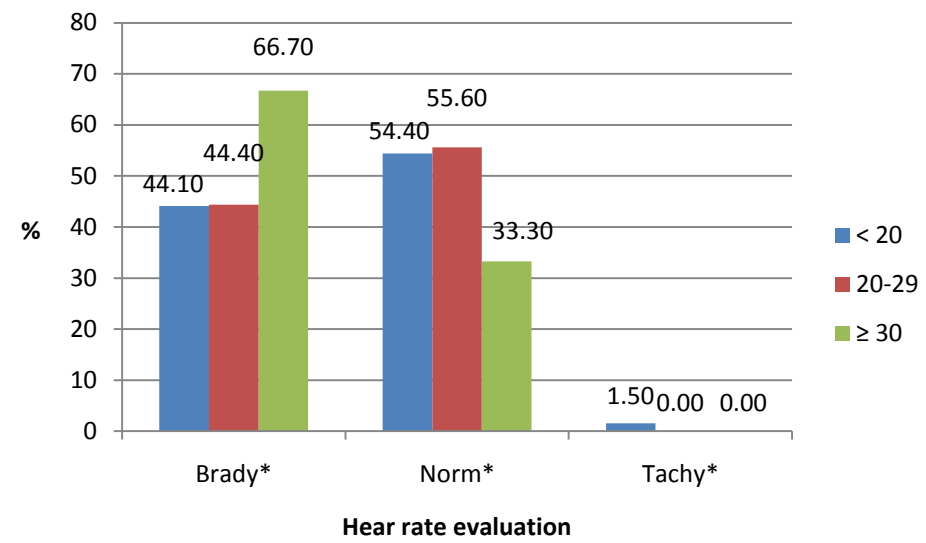

Diagram 2. Heart rate evaluation according to age group for 227 athletes. ${ }^{\star B}$ Brady: bradycardia; Norm: normal heart rate; Tachy: tachycardia; $\mathrm{p}=0.275$. 


\section{Discussion}

\subsection{Weakness and Strengths}

We conducted a study among volunteering footballers, which mean that there is some degree of selection bias and we had only ECG and Echocardiography to perform cardiac evaluation. But this was to the best our knowledge the first study to systematically record ECG and Echocardiography for evaluation among athletes in our case footballers.

In our study we found more male footballer as reported in previous studies by Lahady et al. [9], Tiéla [10] and Mounkoro [11], the 2 latter authors using only ECG. This weak proportion could be explained by the fact that professional football is still widely practiced by men and consideration that football is more a male activity. There is since few years some changes leading to more football practice by girls.

Mean age in our study was $22.18 \pm 4.37$ years which was similar to those reported by Lahady et al. [9] and Rawlins [12] with respectively 25 and 21.

\subsection{ECG Findings}

\section{- Heart Rhythm}

All the subjects were in sinus rhythm contrary to the results of Papadakis et al. [13], Sheikh et al. [14] where some premature beats (PB) were observed. These PB can occur on a healthy heart as on a pathological heart, but disappear in the athlete with the effort.

\section{- Heart Rate}

Sinus bradycardia was frequently found in men and women with no significant difference $(\mathrm{p}=0.168)$. Bradycardia is a common finding among athletes as reported by other authors with $33.9 \%$ for Grosjean [15] and up to $80 \%$ for Sharma et al. [16]. The higher proportion of bradycardia found by Sharma [16] could be due to his population with a longer duration of training as bradycardia is due to an increase in vagal tone secondary to training [15].

\section{- PR Duration}

In sports, AV block (AVB) I is common and a priori benign. He is an indicator for a decrease in sympathetic tone and an increase in parasympathetic tone at rest. It could exist before the sport practice according to Brion [17].

Our study found a prolongation of the PR duration type AVB I in footballers of both sexes without significant difference $(\mathrm{p}=0.199)$. The same phenomenon of PR prolongation was observed by other authors in black and white athletes [1]-[14] with a significant difference [16] $(\mathrm{p}<0.001)$.

\section{- QRS Duration}

We found an incomplete bundle branch block frequency comparable to that reported by Papadakis et al. [13] in 2011. In sport, incomplete right bundle block (RBBB) does not seem to be related to a real conductive disorder of the right branch but to a particular activation of the hypertrophied right ventricle or a vagal mechanism. On the other hand, the complete right branch block, the left 
branch blocks and hemiblocks are not part of the particularities of the athlete's heart. Their discovery still requires a cardiological assessment [16].

The enlarged QRS was observed more in men than in women without a significant difference.

- Sokolov's Index:

The electrical left ventricular hypertrophy (LVH) based on Sokolov Lyon index is more common among athletes.

LVH was significantly found in men than in women with $\mathrm{p}<0.0001$. This result is similar to that of Rawlins et al. [12] where LVH was present in $9.2 \%+$ $1.2 \%$ among male against $8.6 \%+1.2 \%$ among female $(\mathrm{p}<0.0001)$. Constitution (shape and size of the thorax) are also factors that could increase the amplitude of the QRS according to the literature [15] which probably also explain the difference between both sexes.

- Corrected QT Using Bazett Formula: QTc

Bradycardia which is common in athletes leads to a significant lengthening of the QT interval [18].

We found a high frequency of long QTc compared to a similar study done in Bamako by Mounkoro [9] (4.6\%) among footballers under 15 years old. This difference could be related to age, the duration of sports practice leading to more bradycardia in older athletes like in our study. This QTc prolongation not exceeding $500 \mathrm{~ms}$ is usually attributed either to a delay in repolarization due to an increase in left ventricular mass in athletes or to a maladaptation of Bazett's formula to low heart rates [15].

- ST Elevation

It should be noted often, in the high-level athlete, an elevation of the J point followed by an elevation of the ST segment, most often concave upward, horizontal or ascending, and generally followed by a large positive $\mathrm{T}$ wave. This aspect has been called by some authors "early repolarization syndrome".

ST segment elevation was present in more than half of our footballers with a significantly higher frequency in men than in women with $\mathrm{p}<0.0001$. Similar results were reported by Rawlins et al. [12] where ST + was present in $11 \%$ in men versus $1 \%$ in women with $\mathrm{p}<0.001$.

- Negative T Wave

The negative $\mathrm{T}$ wave was frequently found in our footballers with a higher incidence in men than in women with $\mathrm{p}=0.013$. Rawlins et al. [12] found $14 \%$ in men versus $2 \%$ in women with $\mathrm{p}<0.001$.

\subsection{Echocardiographic Findings}

\section{- Interventricular Septum (IVS)}

IVS dimensions ranged from 7 to $16 \mathrm{~mm}$ with an average of $10.65 \mathrm{~mm}$, with hypertrophy in 22 all males, 10.7\%. Lahady et al. [9] reported 46 cases of septal hypertrophy between 11.5 to $16.5 \mathrm{~mm}$ whereas an average of $9.0+-1.3,9.0+1.3$ $\mathrm{mm}$ in female black athletes were reported respectively by Sheikh [14] and Rawlins et al. [12]. 


\section{- Posterior Wall (PW)}

The posterior wall was not very thick in our study $(0.5 \%)$, unlike the result of Lahady et al. [9] who found a higher number of PW hypertrophy. This hypertrophy was significantly correlated with age above 30 years $(\mathrm{p}=0.003)$.

- Indexed Left Ventricle Diameter (LVi)

The LVi was higher for female footballers than for boys, with a statistically significant difference $(\mathrm{p}=0.001)$. Sheikh et al. [14] found no significant difference between the black athlete and the white athlete in the size of the left ventricle.

- The Ejection Fraction (EF)

The average left ventricular EF was similar to that found by Rawlins et al. [12] $(67.4 \%+6.7 \%)$. We also recorded low ejection fractions as reported by Lahady et al. [9].

Summarizing sinus bradycardia, first degree AVB, RBBB, LVH, prolonged QT, ST segment elevation, repolarization disorders, increased LV mass, and increased left ventricle size were the different abnormalities found in our study population.

The frequency of these affections in athletes is due to a phenomenon of adaptation of the heart to intense and regular physical activities called athlete's heart [13]. This adaptation concerns the four cavities with morphological and functional changes that are balanced, homogeneous and proportional.

It concerns aerobic disciplines with high training level ( $>8$ - 10 hours/week, intensity $\left.>60 \% \mathrm{VO}_{2} \max \right)$ with hypertrophy-dilation. Anaerobic training (weightlifting) induces a very predominant concentric hypertrophy of the left ventricle.

\section{Conclusions}

The electrical and echocardiographic modifications of the heart are frequently observed in the high level athletes. This phenomenon of cardiac adaptation is more common in men than in women.

Although the athlete's heart is a benign pathology, it requires strict and regular monitoring by a sports doctor to prevent the risk of sudden death related to ventricular rhythm disorders during physical and intense sports activities.

\section{Conflicts of Interest}

The authors declare no conflicts of interest regarding the publication of this paper.

\section{References}

[1] Carré, F., Comelou, P., Chevalier, L. and Rivière, D. (2006) Adaptations cardiovasculaires à l'exercice musculaire. La Lettre de P Observatoire du Movement, 17, $1-10$.

[2] Thompson, P.D., Franklin, B.A., Balady, G.J., Blair, S.N., Corrado, D., Estes, N.A., Fulton, J.E., Gordon, N.F., et al. (2007) Exercise and Acute Cardiovascular Events. Placing the Risks into Perspective. Circulation, 115, 2358-2368. 
[3] Corrado, D., Basso, C., Rizzoli, G., Schiavon, M., Thiene, G., Schiavon, M., et al. (2003) Does Sports Activity Enhance the Risk of Sudden Death in Adolescents and Young Adults? Journal of the American College of Cardiology, 42, 1959-1963. https://doi.org/10.1016/j.jacc.2003.03.002

[4] Bille, K., Figueiras, D., Schamasch, P., Kappenberger, L., Brenner, J.I., Meijboom, F.J., et al. (2006) Sudden Cardiac Death in Athletes: The Lausanne Recommendations. The European Journal of Cardiovascular Prevention \& Rehabilitation, 13, 859-875. https://doi.org/10.1097/01.hjr.0000238397.50341.4a

[5] 36th Bethesda Conference (2005) Eligibility Recommendations for Competitive Athletes with Cardiovascular Abnormalities. Journal of the American College of Cardiology, 45, 1321-1375.

[6] Pelliccia, A., Fagard, R., Bjornstad, H.H., Anastassakis, A., Arbustini, E., Assanelli, D., et al. (2005) Recommendations for Competitive Sports Participation in Athletes with Cardiovascular Disease: A Consensus Document from the Study Group of Sports Cardiology of the Working Group of Cardiac Rehabilitation and Exercise Physiology and the Working Group of Myocardial and Pericardial Diseases of the European Society of Cardiology. European Heart Journal, 26, 1422-1445. https://doi.org/10.1093/eurheartj/ehi325

[7] Dupuis, J.M., Tabib, A., Reix, P., Dupuis, L., Daudet, G., Jocteur-Monrozier, D., et al. (2005) Mort subite inopinée d'origine cardiaque entre 6 et 18ans. Données anatomopathologiques. Rôle du sport? Prévention? Archives de pédiatrie, 12, 1204-1208. https://doi.org/10.1016/j.arcped.2005.02.006

[8] Chevalier, L., Carré, F., Comelou, P. and Rivière, D. (2006) La mort subite du sportif. La Lettre de I Observatoire du Mouvement, 17, 1-10.

[9] Lahady, R., Derason, G., Andrianjafimanana, C.H., Ranaivo, M., Michel, F., Ratsivalaka, R., et al. (2000) Exploration d'un cœur de sportif de haut niveau. A propos de 100 cas observés dans le service de Radiologie du Centre Hospitalier Régional de Tamatave. Médecine d Afrique Noire, 47, 298-300.

[10] Tiéla, S. (2011) L'étude des particularités électrocardiographiques des candidats au concours d'entrée à l'INJS. Thèse de Médecine, Bamako, No. 263, 1-57. https://www.keneya.net/fmpos/theses/2011/med/pdf/11M263.pdf

[11] Mounkoro, D.B. (2013) Etude électrocardiographique des candidats au concours d'entrée au lycée Ben Oumar SY de Bamako. Thèse de Med, Bamako, No. 205. https://www.keneya.net/fmpos/theses/2013/med/pdf/13M205.pdf

[12] Rawlins, J., Carre, F., Kervio, G., Papadakis, M., Chandra, N., Edwards, C., et al. (2010) Ethnic Differences in Physiological Cardiac Adaptation to Intense Physical Exercise in Highly Trained Female Athletes. American Heart Association, 121, 1078-1085.

[13] Papadakis, M., Carre, F., Kervio, G., Rawlins, J., Panoulas, V.F., Chandra, N., et al. (2011) The Prevalence, Distribution, and Clinical Outcomes of Electrocardiographic Repolarization Patterns in Male Athletes of African/Afro-Caribbean Origin. European Heart Journal, 32, 2305-2312.

[14] Sheikh, N., Papadakis, M., Carre, F., Kervio, G., Panoulas, V.F., Ghani, S., et al. (2013) Cardiac Adaptation to Exercise in Adolescent Athletes of African Ethnicity: An Emergent Elite Athletic Population. British Journal of Sports Medicine, 47, 585-592. https://doi.org/10.1136/bjsports-2012-091874

[15] Grosjean, V. (2012) Le cœur d'athlète chez l'adolescent: Aspects électrocardiographiques et échocardiographiques. A propos de 107 athlètes. Thèse de Médecine, Université Claude Bernard Lyon 1, Lyon, 51-112. 
http://www.clubcardiosport.com/documentation/theses/Valerie-Grosjean-janv-201 2.pdf

[16] Sharma, S., Whyte, G., Elliott, P., Padula, M., Kaushal, R., Mahon, N. and McKenna, W.J. (1999) Electrocardiographic Changes in 1000 Highly Trained Junior Elite Athletes. British Journal of Sports Medicine, 33, 319-324. https://doi.org/10.1136/bjsm.33.5.319

[17] Brion, R., Carré, F., Aupetit, J.F., Douard, H., Abergel, E., Auriacombe, L., et al. (2006) Recommandations sur la conduite à tenir devant la découverte d'une hypertrophie ventriculaire gauche chez un sportif.

https://www.sfcardio.fr/sites/default/files/pdf/RecommandationHVGdusportif2006. pdf

[18] Doucende, G. (2010) Grégory Doucende. Adaptations cardiaques à l'exercice aigu, chronique et épuisant de longue durée: Mise en évidence du rôle clé du mécanisme de torsion-Détorsion dans le remplissage ventriculaire gauche. Médecine humaine et pathologie. Université d'Avignon, Avignon.

https://tel.archives-ouvertes.fr/tel-00630056/ 